\title{
Sinonasal Squamous Papilloma with Orbital Infiltration in an Elderly Nigerian Female, Unusual Presentation of an Uncommon Tumor: A Case Report
}

\author{
Oyeleye A. Oyelakin ${ }^{1}$, Oluyemi Fasina ${ }^{2 *}$, Clement A. Okolo ${ }^{3}$, Funsho J. Akande1, \\ Onyekwere G. Nworgu ${ }^{1,4}$ \\ ${ }^{1}$ Department of Otorhinolaryngology, University College Hospital, Ibadan, Nigeria \\ ${ }^{2}$ Department of Ophthalmology, University College Hospital, University of Ibadan, Ibadan, Nigeria \\ ${ }^{3}$ Department of Pathology, University College Hospital, University of Ibadan, Ibadan, Nigeria \\ ${ }^{4}$ Department of Otorhinolaryngology, University of Ibadan, Ibadan Nigeria \\ Email: *yemifash2000@yahoo.com
}

How to cite this paper: Oyelakin, O.A., Fasina, O., Okolo, C.A., Akande, F.J. and Nworgu, O.G. (2019) Sinonasal Squamous Papilloma with Orbital Infiltration in an Elderly Nigerian Female, Unusual Presentation of an Uncommon Tumor: A Case Report. Case Reports in Clinical Medicine, 8, 134-139.

https://doi.org/10.4236/crcm.2019.85015

Received: April 28, 2019

Accepted: May 26, 2019

Published: May 29, 2019

Copyright $\odot 2019$ by author(s) and Scientific Research Publishing Inc. This work is licensed under the Creative Commons Attribution International License (CC BY 4.0).

http://creativecommons.org/licenses/by/4.0/

\begin{abstract}
Squamous papillomas are squamous-derived growths commonly arising from the oral cavity and oropharynx. A 75-year-old woman presented with chronic persistent left nasal obstruction and gradual painless non-axial proptosis with loss of vision in the left eye. Computed tomography scan showed an iso-dense lesion filling the frontal, left ethmoidal and sphenoidal sinuses, and the nasal cavity, with extension into the left orbit. She underwent surgical tumor resection with orbital exenteration and histology revealed features of an aggressive hyperkeratotic squamous papilloma arising from the sino-nasal region. Although squamous papillomas have been natively associated with the oral cavity and oropharynx, they present less frequently as sino-nasal tumors with orbital invasion.
\end{abstract}

\section{Keywords}

Orbital Tumor, Sino-Nasal Tumor, Proptosis Squamous Papilloma

\section{Introduction}

Papillomas are benign tumours with characteristic papillary projections and are among the most common benign epithelial tumours of the oral cavity in both children and adults, but most commonly seen in persons between 30 and 50 years of age [1]. Squamous papillomas are common, squamous-derived growths 
of the oral cavity and oropharynx typically presenting as a single, asymptomatic, soft, pedunculated mass with numerous finger-like projections at the surface [2] [3]. In the head and neck region, occurrence of this lesion is relatively rare in the paranasal sinuses whereas oral squamous papilloma is the fourth most common mucosal mass in humans accounting for 3\% - 4\% of all biopsied lesions [4].

To the best knowledge of the authors, orbital involvement of this tumor has not been reported in Nigeria; hence, this reports the presentation and management of sino-nasal squamous papilloma with orbital involvement in an elderly Nigerian female.

This study adhered to the Tenets of Declaration of Helsinki and an informed consent was obtained from the patient for the publication of the report.

\section{Case History}

A 75-year-old lady presented with persistent left nasal obstruction of 2 years, and gradual painless protrusion with loss of vision in the left eye of about 6 months duration. There was associated ipsilateral purulent nasal discharge and loss of smell but no history of persistent sneezing, itching, or nosebleed. The right nasal cavity and right eye were symptom-free.

At presentation, the ear, oral cavity, neck, and oropharyngeal examinations were essentially normal. However, there was a pink firm mass in the left nasal cavity with greenish-yellow discharge, no distortion of the nasal pyramid and the airflow was completely obstructed. There was left non-axial proptosis of $12 \mathrm{~mm}$ with inferotemporal globe displacement, conjunctival chemosis, keratinized and opacified cornea, and nil detailed view of intraocular structures. The orbit was filled with a firm soft tissue tumour and visual acuity was nil perception of light. The right ocular examination was essentially normal as she had only early lenticular opacity which was compatible with her age.

Computed tomography scan showed an iso-dense lesion filling the frontal, left ethmoidal and sphenoidal sinuses, nasal cavity and extending into the left orbit (Figure 1). Hematological profile of the patient was essentially normal.

She was reviewed by both the ophthalmologist and otorhinolaryngologist and subsequently underwent left lid-sparing orbital exenteration, with sino-nasal tumour excision via a transorbital ethmoidectomy and trans-nasalapproach. She also had inferior meatal antrostomy which revealed minimal aspirates but no mass was in the maxillary cavities. The sino-nasal tumor mass appears fleshy, polypoid and pale on gross examination. She had intrasanal packing with Bismuth Iodoform Paraffin Paste intra-operatively, and immediate post-operative recovery was satisfactory.

Histopathological sections of the extra-oculartumour showed a benign epithelial neoplasm composed of multiple complex exophytic papillomatous fronds having prominent fibrovascular cone and lined by keratinizing squamous epithelial cells with occasional columnar and mucous containing cells. The basal layer showed occasional mitosis with mild atypia of the lining cells and growth of this tumor stopped short of the globe (Figure 2). Sections of the globe showed 


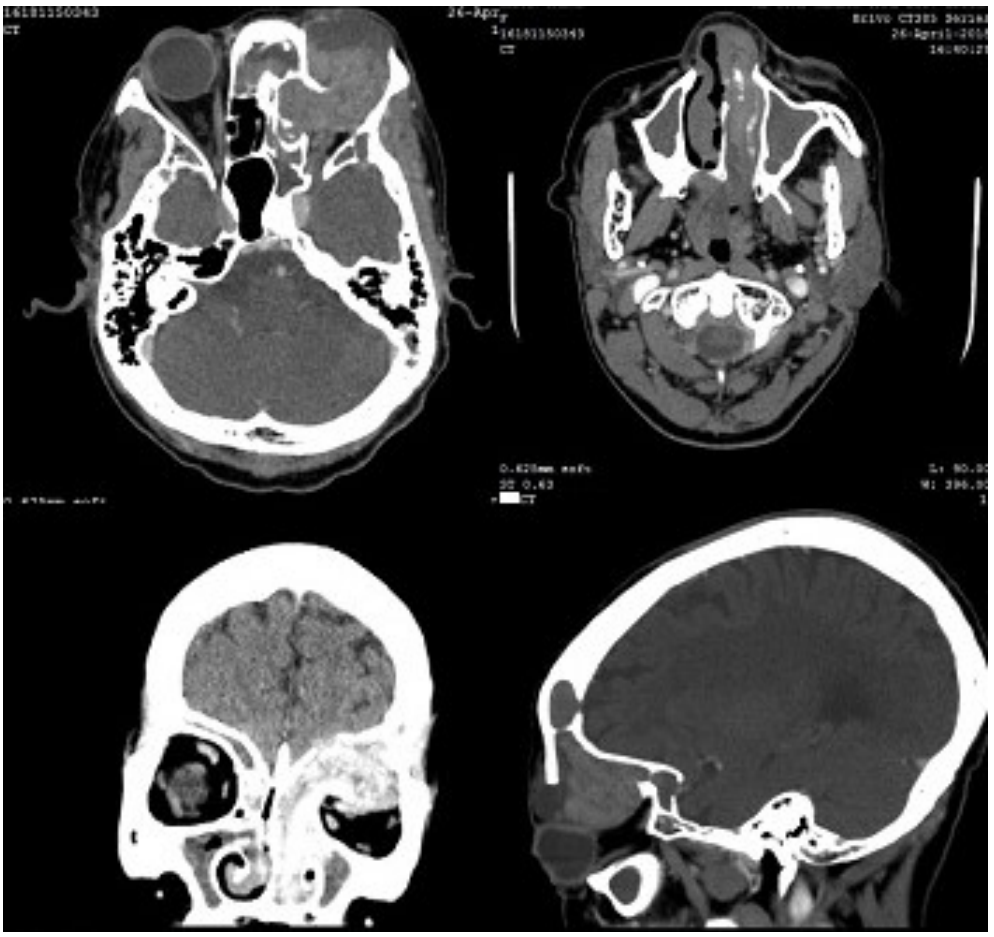

Figure 1. Computed tomography scan showing an iso-dense lesion filling the frontal, left ethmoidal and sphenoidal sinuses, nasal cavity and extending into the left orbit.

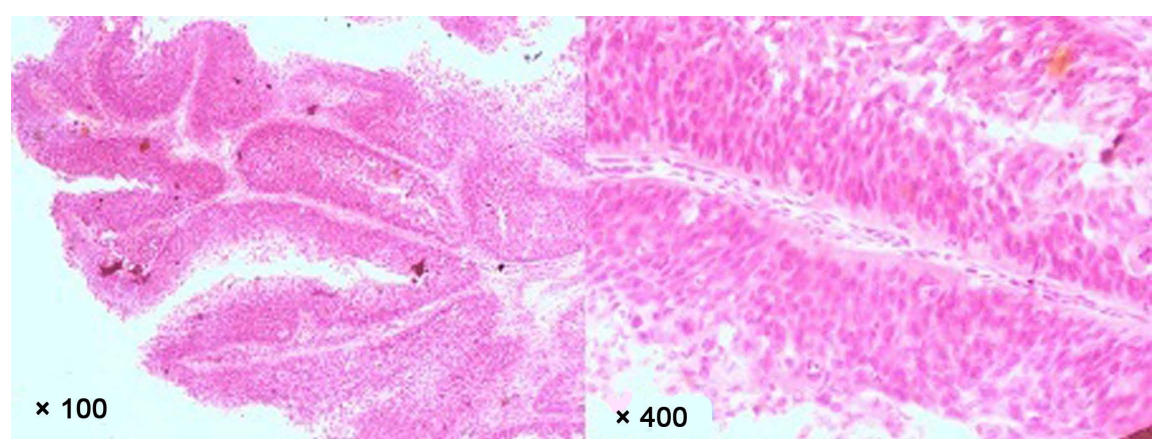

Figure 2. Photomicrograph of the squamous papilloma showing the tumor composed of multiple polypoid fronds of tissue lined by squamous epithelial cells showing mild to moderate cytonuclei-pleomorphism and loss of polarity.

only a fragment of atrophic optic nerve possibly due to compression by the tumour while the globe showed no remarkable features. Overall features were suggestive of an aggressive hyperkeratotic squamous papilloma arising from the sino-nasal region. She fared well post-operatively, and has been followed up for about six months with no recurrence of tumor.

\section{Discussion}

Sino-nasal tumours which extend into the orbits usually arise from the maxilla-ethmoid complex [5], however, the index case had orbital tumor invasion from the superior-medial wall. Orbital invasion from sino-nasal tumors can occur via various anatomic paths and Saha et al. [6] in their study, reported that 
inverted papillomas invaded the orbit via the sphenoid in $4 \%$ of cases, and via erosion of the lamina papyracea in $13 \%$ of cases. Orbital tumors cause proptosis, the anterior protrusion of the eyeball within the orbit and this can be from primary space occupying lesions of the orbit, secondary extension from the para-orbital structures, or distant mestasis. Keche et al. [5] in their review of causes of unilateral proptosis reported that $85 \%$ of unilateral proptosis resulted from para-orbital tumors, $10 \%$ were primary orbital tumors, and $5 \%$ from distant metastasis. Similarly, our patient had unilateral proptosis following orbital tumor invasion from a primary sino-nasal tumor.

Squamous papilloma is benign tumor in the spectrum of papillary tumors affecting the oral cavity [7] and there is a strong association between Human Papilloma Virus and the tumor [1]. The history of progressive nasal obstruction is common to both benign and malignant nasal growths, but nasal obstruction of long duration as reported in this elderly woman is suggestive of a benign pathology [6]. Typically, the involvement of the orbit in sino-nasal tumorsis seen in paraorbital malignant conditions [5], however, when associated with benign conditions, the common pathologies include inverted papilloma, juvenile angiofibroma, fungal sinusitis and other infectious conditions [8] [9] [10] [11].

The differential of the clinical presentation of a yellowish-green nasal discharge and gradual painless proptosis include chronic sino-nasal fungal infection [12] [13]. Although, mycology studies were not carried out on the excised tissue, the histopathological examination did not show typical features suggestive of fungal disease such as the presence of granulomas with refractile fungal hyphae and spores. Epistaxis, facial deformity, diplopia, facial numbness and other features suggestive of malignant sino-nasal tumours [14] were also absent in our patient.

Visual affectation is uncommon in benign orbital conditions [5], however, the long-standing orbital infiltration with severe proptosis, and possibly, compressive optic neuropathy could account for the loss of vision in this elderly woman.

Appropriate imaging is complementary to symptomatology in making a presumptive diagnosis of sino-nasal tumours, however, they are not substitutes to histological diagnosis [15]. Imaging also aids in the determination of tumour margins and attachment sites, and a combination of computed tomography (CT) scan, magnetic resonance imaging (MRI) and positron emission tomography. (PET/CT), could be carried out [16]. The CT scan of the paranasal sinuses and orbits, which is the most preferred radiological imaging, was carried out in the patient. This showed tumor involvement of the paranasal sinuses and orbit, and also, an iso-dense lesion in the left maxillary sinus, which intraoperatively was found to be impeded secretions caused by blockage of the osteo-meatal complex by the tumour.

Definitive treatment of squamous papilloma is basically total surgical excision [3]. Sino-nasal tumors could be removed via endoscopic sinus surgery, by external surgical approach, or a combination of the two [17]. Excision of the tumor by ethmoidectomy via the orbital cavity was appropriate in this case following 
orbital exenteration. The portion of the tumour in the left nasal cavity was easily accessed through the trans-nasal approach with a pair of Luc's forceps.

\section{Conclusion}

In conclusion, although squamous papillomas have been natively associated with the oral cavity and oropharynx, they can present as sino-nasal tumors with orbital invasion. Surgical excision is the mainstay of management of squamous papilloma and histological differentiation from malignant conditions like verrucous carcinoma which is very important to guide the post-operative treatment.

\section{Conflicts of Interest}

The authors declare no conflicts of interest regarding the publication of this paper.

\section{References}

[1] Barnes, L. (2010) Diseases of the Larynx, Hypopharynx, and Trachea. In: Barnes, L., Ed., Surgical Pathology of Head and Neck Surgery, Informa Healthcare, New York, 119.

[2] Lian, T.S. (2010) Benign Tumors and Tumor-Like Lesions of the Oral Cavity. In: Flint, P.W., Haughty, B.H., Lund, V.J., et al., Eds., Cummings Otolaryngology. Head and Neck Surgery, Mosby Elsevier, Philadelphia, 1209. https://doi.org/10.1016/B978-0-323-05283-2.00096-3

[3] Alan, H., Agacayak, S., Kavak, G. and Ozcan, A. (2015) Verrucous Carcinoma and Squamous Cell Papilloma of the Oral Cavity: Report of Two Cases and Review of Literature. European Journal of Dentistry, 9, 453-456.

https://doi.org/10.4103/1305-7456.163224

[4] Singh, A.K., Malik, U., Malhotra, S. and Kumar, A. (2016) Squamous Papilloma: A Report of Two Cases with Review of Literature. Journal of Indian Academy of Oral Medicine and Radiology, 1, 102-104. https://doi.org/10.4103/0972-1363.189978

[5] Keche, P.A., Nitnaware, A.Z., Mair, M., Sakhare, P. and Satpute, S. (2013) A Study of Tumours Giving Rise to Unilateral Proptosis. Indian Journal of Otolaryngology and Head \& Neck Surgery, 65, 6-13. https://doi.org/10.1007/s12070-011-0353-0

[6] Saha, S.N., Ghosh, A., Sen, S., Chandra, S. and Biswas, D. (2011) Inverted Papilloma: A Clinico-Pathological Dilemma with Special Reference to Recurrence and Malignant Transformation. Indian Journal of Otolaryngology and Head \& Neck Surgery, 62, 354-359. https://doi.org/10.1007/s12070-010-0056-y

[7] Thomas, G.J. and Barrett, A.W. (2009) Papillary and Verrucous Lesions of the Oral Mucosa. Diagnostic Histopathology, 15, 279-285. https://doi.org/10.1016/j.mpdhp.2009.03.006

[8] Prabhakar, S.K., Bharathi, M.B. and Kumar, S.A. (2016) Recurrent Inverted Papilloma of Paranasal Sinus Presenting as Acute Proptosis. Romanian Journal of Ophthalmology, 60, 255-259.

[9] Paknezhad, H., Borchard, N.A., Charville, G.W., Ayoub, N.F., Choby, G.W., Thamboo, A., et al. (2017) Evidence for a "Preinvasive" Variant of Fungal Sinusitis: Tissue Invasion without Angioinvasion. World Journal of Otorhinolaryngology-Head and Neck Surgery, 3, 37-43. https://doi.org/10.1016/j.wjorl.2017.01.003 
[10] Mukherjee, B., Raichura, N.D. and Alam, M.S. (2016) Fungal Infections of the Orbit. Indian Journal of Ophthalmology, 64, 337-345. https://doi.org/10.4103/0301-4738.185588

[11] Das, S., Kirsch, C.F.E., Infirmary, L.R., Hospital, R.L. and Road, W. (2005) Imaging of Lumps and Bumps in the Nose: A Review of Sinonasal Tumours. Cancer Imaging, 5, 167-177. https://doi.org/10.1102/1470-7330.2005.0111

[12] Montone, K.T. (2016) Pathology of Fungal Rhinosinusitis: A Review. Head and Neck Pathology, 10, 40-46. https://doi.org/10.1007/s12105-016-0690-0

[13] Suresh, S., Arumugam, D., Zacharias, G. and Venkatraman, V. (2016) Prevalence and Clinical Profile of Fungal Rhinosinusitis. Allergy \& Rhinology, 7, 115-120. https://doi.org/10.2500/ar.2016.7.0156

[14] Shirazi, N., Bist, S.S., Selvi, T.N. and Harsh, M. (2015) Spectrum of Sinonasal Tumors: A 10-Year Experience at a Tertiary Care Hospital in North India. Oman Medical Journal, 30, 435-440. https://doi.org/10.5001/omj.2015.86

[15] Kulkarni, A.M., Mudholkar, V.G., Acharya, A.S. and Ramteke, R.V. (2012) Histopathological Study of Lesions of Nose and Paranasal Sinuses. Indian Journal of Otolaryngology and Head \& Neck Surgery, 64, 275-279.

https://doi.org/10.1007/s12070-011-0286-7

[16] Sun, Q., An, L., Zheng, J. and Zhu, D. (2017) Advances in Recurrence and Malignant Transformation of Sinonasal Inverted Papilloma. Oncology Letters, 13, 4585-4592. https://doi.org/10.3892/ol.2017.6089

[17] Darwish, A. and Al-abdulla, A. (2012) Cylindrical Cell Papilloma (Oncocytic Schneiderian Papilloma): Clinicopathological Study of Five Cases. Oman Medical Journal, 27, e039. 